\title{
Effect, Adverse Events and Re-operations after Tension-free Vaginal Tape Obturator Surgery
}

\author{
Silja Maigaard Axelsen (iD ${ }^{*}$, Rikke Guldberg Sørensen, MD, PhD and Susanne Axelsen, MD, PhD
}

Department of Obstetrics and Gynecology, Aarhus University Hospital, Denmark

*Corresponding author: Silja Maigaard Axelsen, Stud.Med, Department of Obstetrics and Gynecology, Aarhus University Hospital, Denmark, Tel: +45-2614-7103

\begin{abstract}
Background: Women with stress urinary incontinence can be offered an operation with mid-urethral sling. First, Tension-free vaginal tape was invented. Some years later, because of concerns about complications associated with this operation, the other minimally invasive procedure using the trans obturator procedure was introduced by Dr. J. de Leval in 2003. Since then, the diversity in methods gave rise to a discussion of both efficacy, complications and reoperations. In Denmark, the professional discussion about Tension-free Vaginal Tape Obturator is ongoing, which is an important reason for evaluating the patient-reported outcome of this type of operation. The aim was to evaluate patient-reported outcome, adverse events and reoperations after Tension-free Vaginal Tape Obturator operations.
\end{abstract}

Methods: During a five-year period, prospective data from the Danish Urogynecological Database were collected regarding Tension-free Vaginal Tape Obturator operations performed at the Department of Gynecology and Obstetrics, Aarhus University Hospital. Effect was evaluated using data from validated questionnaires filled in by the women before and after the operation. Adverse events and reoperations were collected at follow-up from the registration in the database.

Results: Total number of women included was 377 . Of these, $83.8 \%$ were followed with a mean follow-up period of 17 months ( $16.2 \%$ was lost for follow-up). The effect of the Tension-free Vaginal Tape Obturator operations reported by the women was $85 \%$. Adverse events like leg- or groin pain, urinary retention, infection, hematoma and bleeding were experienced by $13.9 \%$. Reoperations because of perforation of urethra, erosion of vaginal mucosa, urgency incontinence symptoms, adjusting or removing sling and general inconveniences were performed in $3.8 \%$ of the women. Patient characteristics were similar in the group with good effect as well as the groups with adverse events and reoperations. At baseline, $27.2 \%$ women reported urgency incontinence (UUI) together with their stress incontinence. At follow-up, the number of UUI was reduced to $13.9 \%$ women. De novo UUI symptoms were experienced by $7.3 \%$ of the women at follow-up.

Conclusion: The study showed a subjective improvement and effect among women undergoing Tension-free Vaginal Tape Obturator operations comparable to previous studies. Adverse events due to the operation were not frequent and only 12 women needed re-operations. About half of the women who had mixed urinary incontinence at baseline got rid of the urgency incontinence as well as stress incontinence symptoms after the operation. A small group of women developed de novo urgency incontinence symptoms after the operation.

\section{Keywords}

Stress incontinence, Urgency incontinence mid-urethral sling, Tension-free Vaginal Tape Obturator, Patient-reported outcome

\begin{abstract}
Abbreviations
DugaBase: Danish Urogynecological Database; MUS: Mid-Urethral Sling; SUI: Stress Urinary Incontinence; TVT-O: Tension-free Vaginal Tape Obturator; TVT: Tension-free Vaginal Tape; UUI: Urgency Urinary Incontinence
\end{abstract}

\section{Introduction}

Urinary incontinence (UI) is a very common and debilitating problem and affects $50 \%$ of women at some point in their lives. Stress urinary incontinence (SUI) is a predominant cause in 30 to $80 \%$, imposing significant health and economic burden on society and the women affected [1]. For more than 20 years, gynecologists all over the world have been able to offer an operation for

Citation: Axelsen SM, Sørensen RG, Axelsen S (2019) Effect, Adverse Events and Re-operations after Tension-free Vaginal Tape Obturator Surgery. Int Arch Urol Complic 5:067. doi.org/10.23937/24695742/1510067

Accepted: December 16, 2019: Published: December 18, 2019

Copyright: (c) 2019 Axelsen SM, et al. This is an open-access article distributed under the terms of the Creative Commons Attribution License, which permits unrestricted use, distribution, and reproduction in any medium, provided the original author and source are credited. 
SUI with an acceptable long-term efficacy [1]. Mid-urethral sling (MUS) involves the passage of a small strip of tape through either the retropubic (Tension-free Vaginal Tape, TVT) or obturator space (Tension-free Vaginal Tape Obturator, TVT-O), with entry or exit points at the lower abdomen or groin, respectively.

TVT was invented in Sweden in 1995 and introduced in Denmark two years later. In 2001, concerns about complications associated with TVT led to the development of another MUS technique using the trans obturator procedure [2]. Most gynecological departments in Denmark chose either the retropubic or the trans obturator technique. The diversity in technique gave rise to a professional discussion of both efficacy, complications and reoperations [3-5]. Since the worldwide introduction of the trans obturator MUS, a similar comparison was seen in the literature $[2,6]$. The TVT-O operation is criticized for more comprehensive post-operative complications than TVT, which may lead to subsequent operations [7]. On the other hand, the TVT-O operation has shown to cause lower rates of bladder perforation, operation time, perioperative blood loss, admission time and postoperative frequent voiding dysfunction than TVT $[1,8]$.

In 2014, Laurikainen, et al. compared TVT and TVT-O in a long term randomized controlled trial [9]. In the 2017 edition of the Cochrane review of MUS for SUI, the conclusion was that irrespective of the routes traversed, the different methods were highly effective in the short and medium term [1]. Concerning complications, fewer were seen with employment of a trans obturator approach with the exception of groin pain. But the authors of the review also concluded that there is a need for reporting of longer-term outcome data. In a retrospective study, Rajendra, et al. concluded that TVT-O is effective and safe [10].

\section{Objectives}

In Denmark, the professional discussion about Tension-free Vaginal Tape Obturator is ongoing, which is an important reason for evaluating the patient-reported outcome of this type of operation. The aim of this study was to provide clarification regarding uncertainties about effectiveness, adverse events and reoperations for women operated with TVT-O in a Danish context.

\section{Methods}

The study is a cohort study with 377 women who were followed up during a five-year period from 20122016. In Denmark, all operations for urinary incontinence are mandatory by law reported in a nationwide database, the Danish Urogynaecological Database (DugaBase). The Database was established in 2006 to monitor, ensure and improve the quality of urogynaecological surgery [11]. During the five-year period, data from the DugaBase were reviewed for women who underwent a urinary incontinence procedure with the
ICD-10 procedure code KLEG10A at Aarhus University Hospital. The operations were performed from 2010 to 2016 by four experienced operating surgeons. The surgeons used the same operation techniques. All operations were performed using local anesthesia and included a cough stress test in the end of the operation. The majority of women completed questions from the International Consultation on Incontinence - Urinary Incontinence Short Form (ICIQ-UI SF).

ICIQ-UI SF was used to evaluate the severity of urinary incontinence and its impact on health-related quality of life. The short form contains three scored items and a non-scored self-diagnostic item. A total score for the three scored items was calculated by adding them up. A score of 0 indicates a totally continent patient. Maximum score for worst incontinence is 21 [12]. The patient's urinary incontinence inconveniences were evaluated as a subjective effect divided into three grades: Non/few inconveniences (0-2), some inconveniences (3-6) and many inconveniences (7-10). Demographic data included age at the time of operation, body mass index (BMI), number of vaginal deliveries, smoking status and previous prolapse and incontinence operations.

Women included in the present study were operated at the Department of Gynecology and Obstetrics, Aarhus University Hospital, Denmark. The MUS used was the "in-out" trans obturator tape, TVT-O (Gynecare, Johnson-Johnson Company). Postoperative follow-up was performed by a personal or telephone interview. Pre- and postoperatively, an identical questionnaire was filled in by the women. To complete the database, missing data were collected by telephone interview. Contact was established by telephone three times before the patient was categorized as lost for follow-up.

\section{Statistical analyses}

Descriptive statistic was used to characterize the study population before and after the operation. Adverse events and reoperations were described according to the type of complication and reason for reoperation. The patient characteristics between the group with no complications and the group with complications plus the group not reoperated and the group reoperated were analyzed using 2-sample t-test and Chi-squared test for continuous variables. Pre-surgery characteristics and symptom load between the ones with follow-up and those without were compared, using the t-test and Chi-squared test for trend as above. $\mathrm{P} \leq 0.05$ was considered significant. Excel was used as statistical analysis software.

\section{Ethical Approval}

All women were informed and accepted that their data were registered in a national database. All women 


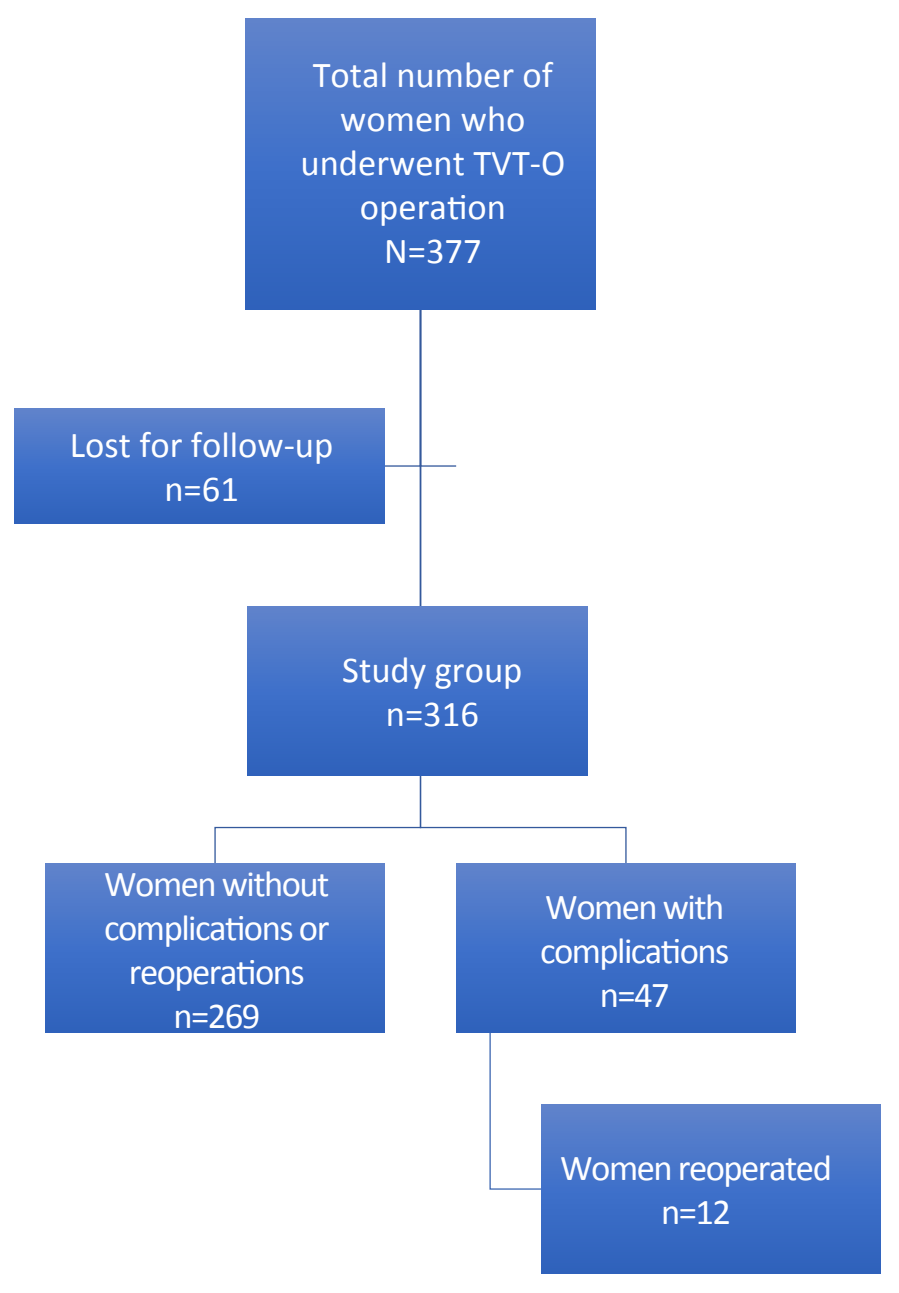

Figure 1: Study participants.

Table 1: Characteristics of women operated with TVT-O for stress urinary incontinence from 2012 to 2016 at the Gynecological Department, Aarhus University Hospital, Denmark $(n=377)$.

\begin{tabular}{|c|c|c|c|c|}
\hline & $\begin{array}{l}\text { Women without adverse } \\
\text { events or reoperations, } \\
\text { reference }(n=269)\end{array}$ & $\begin{array}{l}\text { Total number of } \\
\text { women with adverse } \\
\text { events }(n=47)\end{array}$ & $\begin{array}{l}\text { Women operated } \\
\text { because of adverse } \\
\text { events }(n=12)\end{array}$ & $\begin{array}{l}\text { Women lost for } \\
\text { follow-up }(n=61)\end{array}$ \\
\hline $\begin{array}{l}\text { Age at operation, mean } \\
\text { (SD), years }\end{array}$ & $50(10.75)$ & $\begin{array}{l}53(12.61) \\
{[p=0.13]^{*}}\end{array}$ & $\begin{array}{l}50(8.89) \\
{[p=1.0]^{\star}}\end{array}$ & $\begin{array}{l}48(9.32) \\
{[p=0.14]^{*}}\end{array}$ \\
\hline $\begin{array}{l}\text { Body mass index, mean } \\
\text { (SD) }\end{array}$ & $25.51(4.35)$ & $\begin{array}{l}25.89(5.39) \\
{[p=0.67]^{\star}}\end{array}$ & $\begin{array}{l}26.94(8.66) \\
{[p=0.57]^{\star}}\end{array}$ & $\begin{array}{l}24.79(5.09) \\
{[p=0.31]^{*}}\end{array}$ \\
\hline Current smoker, n (\%) & $38(14.1)$ & $4(8.5)[p=0.36]^{* *}$ & $\begin{array}{l}0(0) \\
{[p=0.16]^{* *}}\end{array}$ & $\begin{array}{l}9(14.8) \\
{[p=0.90]^{* *}}\end{array}$ \\
\hline $\begin{array}{l}\text { Previous UI surgery, } n \\
(\%)\end{array}$ & $15(5.6)$ & $\begin{array}{l}1(2.1) \\
{[p=0.06]^{* *}}\end{array}$ & $\begin{array}{l}1(8.3) \\
{[p=0.75]^{* *}}\end{array}$ & $\begin{array}{l}3(4.9) \\
{[p=0.84]^{* *}}\end{array}$ \\
\hline $\begin{array}{l}\text { Previous prolapse } \\
\text { surgery, n (\%) }\end{array}$ & $31(11.5)$ & $\begin{array}{l}1(2.1) \\
{[p=0.06]^{* *}}\end{array}$ & $\begin{array}{l}0(0) \\
{[p=0.21]^{* *}}\end{array}$ & $\begin{array}{l}6(9.8) \\
{[p=0.80]^{* *}}\end{array}$ \\
\hline
\end{tabular}

"2-sample t-test, " ${ }^{* *}$ Chi-squared test for trend.

were informed and accepted that they were contacted after the operation and had given their consent to be contacted for follow-up.

The DugaBase operates under the Danish law on data protection, with license granted by the Danish Data Protection Agency and the Danish Health and Medicines Authority. This specific study has been ap- proved by the Danish Data Protection Agency (jr. nr. 15/38617). According to Danish law, ethical approval is not required for purely registry-based studies.

\section{Results}

In the study period, 377 TVT-O operations were registered in the DugaBase. From these, 316 women 
(83.8\%) were included in the follow-up (Figure 1). Sixty-one women (16.2\%) were lost for follow-up. The mean follow-up period was 17 (3-65) months.

Comparing the women with completed follow-up questionnaire to the women lost for follow-up there were no significant difference in the characteristics (age, body mass index (BMI), current smoking and previous $\mathrm{UI}$ and prolapse surgery). Referring to the women without adverse events or reoperations, we found no significant differences in the characteristics comparing them to the groups with adverse events and reoperations (Table 1).

\section{Effect}

The effect of the operation was shown by the women's satisfaction after surgery. Pre- and postoperatively, the same questionnaire was filled in. During the observation period, 377 women had a TVT-O operation in the period but only 339 filled in the questionnaire preoperatively. Postoperatively, 316 women filled in the questionnaire. The reported $\mathrm{UI}$ inconveniences at baseline and at follow-up are shown in Figure 2.
At baseline, $84.7 \%$ of the women reported many inconveniences. At follow-up, inconveniences were only reported by $4.1 \%$. At follow-up, $84.9 \%$ reported non/ few inconveniences, while only $0.9 \%$ of the women reported non/few inconveniences before surgery.

The distribution of inconveniences at follow-up for women who required a second procedure after failure of the TVT-O operation $(n=12)$ was $(0-2)=50.0 \%,(3-6)$ $=41.7 \%$ and $(7-10)=8.3 \%$.

The majority of the 316 women with complete follow-up data reported that the TVT-O operation have made them continent. A total of 245 women (77.5\%) answered, that they never experienced urinary incontinence after the TVT-O operation. Only nine women found their condition after surgery unchanged compared to their UI before the operation. These nine women were treated as shown in Table 2.

At baseline, 86 (27.2\%) women from the study group reported urgency incontinence (UUI) together with their stress incontinence which was the indication of the TVT-operation. At follow-up, the number of UUI was reduced to 44 (13.9\%) women. Of these,

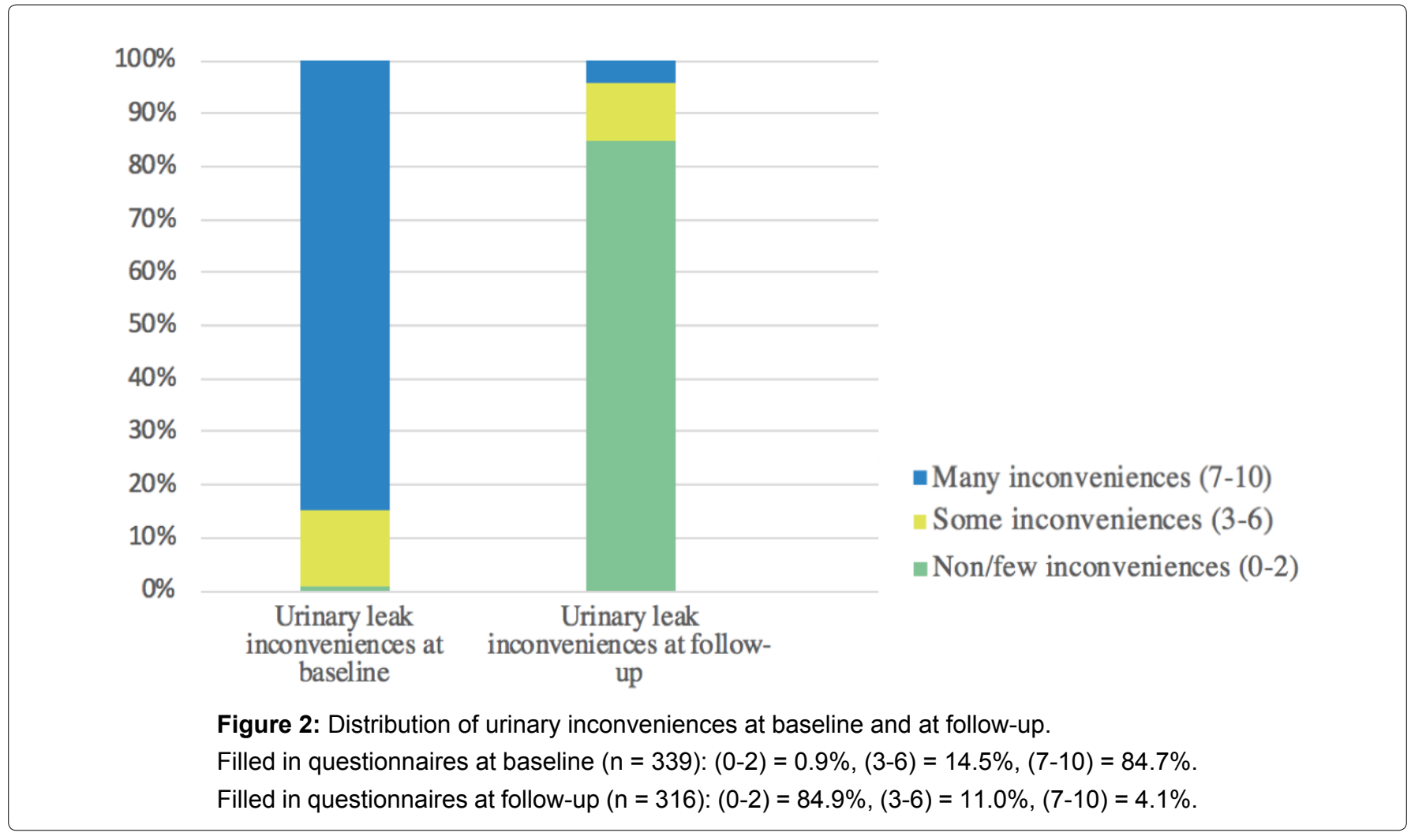

Table 2: Treatment of persistent urinary incontinence after TVT-O operation.

\begin{tabular}{|l|l|}
\hline Treatment of persistent urinary incontinence & Number of women $(\mathbf{n}=\mathbf{9})$ \\
\hline Urgency incontinence treated with medicine & $5(55.6 \%)$ \\
\hline Urgency incontinence, but not wanting treatment with medicine & $1(11.1 \%)$ \\
\hline $\begin{array}{l}\text { Stress urinary incontinence but not wanting any treatment } \\
\text { TVT-O mesh removed because of exposure, offered a McGuire sling but not wanting a new } \\
\text { operation }\end{array}$ & $1(11.1 \%)$ \\
\hline $\begin{array}{l}\text { Primary TVT-O sling loosened because of retention. Hereafter, urgency urinary incontinence. } \\
\text { Treated with medicine with good effect }\end{array}$ & $1(11.1 \%)$ \\
\hline
\end{tabular}


Table 3: Causes of complications.

\begin{tabular}{|l|l|}
\hline Complications & $\begin{array}{l}\text { Number of } \\
\text { women }(\mathbf{n}=47)\end{array}$ \\
\hline $\begin{array}{l}\text { Leg- or groin pain: } \\
\text { Short-duration (7-14 days) } \\
\text { Long-duration (more than 14 days) }\end{array}$ & $\begin{array}{l}10(21.3 \%) \\
\text { (6.4\%) }\end{array}$ \\
\hline $\begin{array}{l}\text { Urinary retention: } \\
\text { Short-duration (less than 7 days) } \\
\text { Long-duration (more than 7 days) }\end{array}$ & $8(17 \%)$ \\
\hline $\begin{array}{l}\text { Infection (including urinary tract } \\
\text { infection) }\end{array}$ & $4(8.5 \%)$ \\
\hline Hematoma & $8(17 \%)$ \\
\hline Intra-operative bleeding & $2(4.3 \%)$ \\
\hline $\begin{array}{l}\text { Mesh exposition with erosion of vaginal } \\
\text { mucosa or urethra }\end{array}$ & $4(8.5 \%)$ \\
\hline Others (dysuria, dyspareunia) & $4(8.5 \%)$ \\
\hline
\end{tabular}

Table 4: Causes of reoperations.

\begin{tabular}{|l|l|}
\hline Reoperation causes & $\begin{array}{l}\text { Number of } \\
\text { women } \mathbf{( n = 1 2 )}\end{array}$ \\
\hline $\begin{array}{l}\text { Slacking of string because of symptoms } \\
\text { due to tight sling }\end{array}$ & $4(33.3 \%)$ \\
\hline $\begin{array}{l}\text { New mid-urethral sling due to mesh } \\
\text { exposition in vaginal mucosa }\end{array}$ & $3(25.0 \%)$ \\
\hline $\begin{array}{l}\text { New mid-urethral sling due to perforation } \\
\text { of urethra at primary operation }\end{array}$ & $2(16.7 \%)$ \\
\hline $\begin{array}{l}\text { Tightening of sling because of symptoms } \\
\text { due to slack sling }\end{array}$ & $1(8.3 \%)$ \\
\hline $\begin{array}{l}\text { New mid-urethral sling due to abundant } \\
\text { bleeding at primary operation }\end{array}$ & $1(8.3 \%)$ \\
\hline $\begin{array}{l}\text { Removal of sling because of unknown } \\
\text { inconveniences }\end{array}$ & $1(8.3 \%)$ \\
\hline
\end{tabular}

21 women both suffered from UUI at baseline and at follow-up. Twenty-three (7.3\%) women experienced de novo UUI symptoms at follow-up.

\section{Adverse events and reoperations}

Five women (1.6\%) did actually experience an undefined urinary incontinence condition which was considerably worse than before surgery. There were no obvious similarities between these five women. All five women accepted a consultation invitation to the outpatient clinic at the follow-up interview. The results of the follow-up visits were not known when writing this manuscript.

Complications after the TVT-O operation were experienced by $14.8 \%(n=47)$ of the women. Twelve women (3.8\%) were reoperated. The most frequent complications were urinary retention, leg- and groin pain and infection (Table 3 ). The re-operational causes were slacking the sling because of symptoms due to the sling being too tight, perforation of urethra or exposition of mesh through the vaginal mucosa (Table 4). Three women experiences exposure of the mesh after the MUS operation. One felt the exposure after eight weeks and was operated immediately with excision. One was diagnosed after five months and had part of the mesh excised after 11 months. One was diagnosed 14 months after the primary operation and had the exposed part of the mesh covered by the vaginal mucosa after 15 months. None of the three women had recurrence of exposure.

\section{Discussion}

In the light of an ongoing professional discussion about TVT-O versus TVT surgery, this study showed that women undergoing TVT-O surgery for SUI at the Department of Gynecology and Obstetrics, Aarhus University Hospital experienced an overall improvement of their Ul symptoms. The effect of the operation was shown by the women's satisfaction after surgery where $84.9 \%$ reported none or few inconveniences. This played a prominent role in both the women's physical symptoms after TVT-O operation and in their evaluation of subjective inconveniences from UI. The efficacy of the TVT-O operation in the present study was comparable to studies from other departments $[7,13,14]$. Natale, et al. found a subjective cure rate of $62.6 \%$ in their long-term follow-up study of the "out-in" trans obturator tape operation which was lower than our $84.9 \%$. One reason might be that they had only $25.2 \%$ women with pure SUI in their entire sample [14]. In our study, with less follow-up time, we had $72.8 \%$ with SUI. Furthermore, a study from Serati, et al. shows a subjective effect of 97\% [15]. This study includes pure SUI patients only. The deviations in study populations might explain the differences in subjective cure rates. As in our study, Natale, et al. found a reduction in urgency incontinence after the operation and a similar percentage of de novo urgency [14].

We showed a low number of adverse events and reoperations. A 6-13 months follow-up study found similar low complication rates for TVT-O. Neuman also showed that TVT-O patients seemed to have less intra-operative and post-operative surgical complications compared to TVT patients [6]. The two techniques were not compared in the present study, but nevertheless, we found the same low rates of intraoperative and postoperative adverse events.

The study indicated a relatively small proportion of women who required a second procedure after failure of the TVT-O operation. It has earlier been described that a repeat TVT-O operation is associated with poor results and is a practice that is not evidence-based [3]. The women's subjective satisfaction at follow-up was lower in the group of women who was re-operated compared to the group of women without adverse events or reoperations. Overall, the group of re-operated women had a mean BMI that was higher than the other groups. Even though, the difference in BMI was not significant the tendency could be considered 
as an explanation why these women experienced adverse events resulting in re-operations and reduced effect of the operation.

It has been described, that the palpable tape remains a major concern, particularly for women who underwent TVT-O surgery (versus TVT), but that a longer-term follow-up may be warranted [2]. In this prospective fiveyear follow-up study with a mean follow-up time of 17 months, none of the participants mentioned palpable tape as a concern. The palpable tape which possibly later could lead to tape exposure and erosion of the vaginal mucosa was only seen in one patient. That is, in our study palpable tape is not considered as a major concern.

We showed that almost half of the women who reported mixed incontinence with urgency urinary incontinence (UUI) symptoms at baseline did not suffer from UUI symptoms at follow-up. Natale, et al. found the same results [14]. The TVT-O operation has a very high effect on treating SUI but can cause continued or emerging UUI symptoms. Some women will even experience increased urgency sensations after surgery [13]. Fortunately, we could repeat the results from the review by Jain, et al.

\section{Limitations}

More than 10 operations per year are needed to maintain a sufficient level of routine [16]. Regarding this recommendation, the study group consisting of 377 TVT-O operations is considered as a sufficient population for surgeon's routine. Nevertheless, this study also has weaknesses. Sixty-one women (16.2\%) were lost for follow up even after three times attempted contacts by telephone. Even though there were no significant differences in the characteristics between the study group and the women lost for follow-up, selection bias cannot be excluded.

Another limitation of the study is that we had no data on conservative treatment after surgery (lifestyle advice, pelvic floor muscle training etc.). Different kinds of conservative treatment could have influenced the women's progress after surgery in both positive and negative directions.

In general, we achieved a high proportion of follow-up data (83.8\%). Yet, not all women were followed during the five-year follow-up period. The follow-up time was varying because some women completed an interview postoperatively while others did not. To complete the database, missing data were collected by telephone interviews. For some women, these telephone interviews were made after several years. This could affect the results. On one hand, women who were interviewed shortly after the operation could not report longtime complications. On the other hand, women who have been interviewed after a long time might have problems recalling de- tails about their progress, or they could have developed other symptoms (e.g. urgency- or prolapse symptoms), which do not necessarily have something to do with the TVT-O operation. These women would probably report their UI condition worse than women without any other symptoms.

The largest uncertainty is the limitations in categorization of the women's subjective view on their general condition, adverse events and reoperations. In the DugaBase, for instance adverse events are reported with yes/no and then a line of free text. The filling in of the free text is dependent on the interviewer and how the interviewer interprets the information from the patient. Because of many different interviewers, the validity of the categorization of answers in the DugaBase could be questioned.

\section{Conclusion}

In conclusion, this study showed a major subjective improvement and effect among women undergoing TVT-O operation at the Department of Gynecology and Obstetrics, Aarhus University Hospital comparable to international departments. Adverse events due to the operation were not frequent and seen as leg- or groin pain, urinary retention, infection, hematoma and bleeding. Few women needed re-operation based on perforation of urethra, erosion of vaginal mucosa, urgency incontinence symptoms, adjusting or removing sling and general inconveniences. About half of the women who had mixed urinary incontinence at baseline got rid of urgency incontinence as well as stress incontinence symptoms after the operation. A small group of women developed de novo urgency incontinence symptoms after the operation. Equivalent research for TVT operations should be made for the purpose of further resemblance.

\section{Acknowledgements}

This study is made in cooperation between the authors. The authors' contributions are as follows:

Silja Maigaard Axelsen: Project execution, data collection, data analysis and manuscript writing.

Rikke Guldberg Sørensen: Data processing, data analysis and manuscript editing.

Susanne Axelsen: Project development, data analysis and manuscript writing.

The three authors declare no conflict of interest.

No specific funding in relation to the study was obtained.

\section{References}

1. Ford AA, Rogerson L, Cody JD, Aluko P, Ogah JA (2017) Mid-urethral sling operations for stress urinary incontinence in women. The Cochrane database of systematic reviews 7: Cd006375. 
2. Ross S, Tang S, Eliasziw M, Lier D, Girard I, et al. (2016) Transobturator tape versus retropubic tension-free vaginal tape for stress urinary incontinence: 5-year safety and effectiveness outcomes following a randomised trial. Int Urogynecol J 27: 879-886.

3. Foss Hansen M, Lose G, Kesmodel US, Gradel KO (2016) Reoperation for urinary incontinence: A nationwide cohort study, 1998-2007. Am J Obstet Gynecol 214: e1-e8.

4. Daneshgari F, Kong W, Swartz M (2008) Complications of mid urethral slings: Important outcomes for future clinical trials. J Urol 180: 1890-1907.

5. Novara G, Galfano A, Boscolo-Berto R, Secco S, Cavalleri $S$, et al. (2008) Complication rates of tension-free midurethral slings in the treatment of female stress urinary incontinence: A systematic review and meta-analysis of randomized controlled trials comparing tension-free midurethral tapes to other surgical procedures and different devices. Eur Urol 53: 288-308.

6. Neuman M (2007) TVT and TVT-Obturator: Comparison of two operative procedures. Eur J Obstet Gynecol Reprod Biol 131: 89-92.

7. Ogah J, Cody DJ, Rogerson L (2011) Minimally invasive synthetic suburethral sling operations for stress urinary incontinence in women: A short version Cochrane review. Neurourol Urodyn 30: 284-291.

8. Latthe PM, Foon R, Toozs-Hobson P (2007) Transobturator and retropubic tape procedures in stress urinary incontinence: a systematic review and meta-analysis of effectiveness and complications. BJOG: An International Journal of Obstetrics and Gynaecology 114: 522-531.
9. Laurikainen E, Valpas A, Aukee P, Kivela A, Rinne K, et al. (2014) Five-year results of a randomized trial comparing retropubic and transobturator midurethral slings for stress incontinence. Eur Urol 65: 1109-1114.

10. Rajendra M, Han HC, Lee LC, Tseng LA, Wong HF (2012) Retrospective study on tension-free vaginal tape obturator (TVT-O). Int Urogynecol J 23: 327-334.

11. Guldberg R, Brostrom S, Hansen JK, Kaerlev L, Gradel $\mathrm{KO}$, et al. (2013) The danish urogynaecological database: Establishment, completeness and validity. Int Urogynecol J 24: 983-990.

12. Ugianskiene A, Kjaergaard N, Inger Lindquist AS, Larsen T, Glavind K (2017) Retrospective study on de novo postoperative urinary incontinence after pelvic organ prolapse surgery. Eur J Obstet Gynecol Reprod Biol 219: 10-14.

13. Jain P, Jirschele K, Botros SM, Latthe PM (2011) Effectiveness of midurethral slings in mixed urinary incontinence: $A$ systematic review and meta-analysis. Int Urogynecol J 22: 923-932.

14. Natale F, Illiano E, Marchesi A, La Penna C, Costantini E (2019) Transobturator tape: Over 10 years Follow-up. Urology 129: 48-53.

15. Serati M, Braga A, Athanasiou S, Tommaselli GA, Caccia G, et al. (2017) Tension-free vaginal tape-obturator for treatment of pure urodynamic stress urinary incontinence: Efficacy and adverse effects at 10-year Follow-up. Eur Urol 71: 674-679.

16. Ammendrup AC, Sorensen HC, Sander P, Lose G (2010) Surgical treatment of female urinary incontinence. Ugeskrift for laeger 172: 456-460. 